\title{
Analysis on Improvement of Service Quality in China's Domestic Worker Market from the Perspective of Psychological Ownership
}

\author{
Houceng \\ Department of Business Management \\ Jilin Business and Technology College \\ Jilin Province, Changchun \\ 770696641@qq.com
}

\begin{abstract}
Based on the current situation of domestic worker market, major problems currently existing in China's domestic worker market are discussed in this paper and those reasons why these problems exist are analyzed from various perspectives, for which psychological factors are considered the underlying causes. On this basis, the concept of psychological ownership and the route for opening up psychological ownership of domestic workers are put forward, which provide some references for solving various problems existing in the current domestic worker market to a certain degree.
\end{abstract}

\section{Keywords-Domestic Worker Market; Service Quality; Psychological Ownership \\ I. ANALYSIS ON THE CURRENT SITUATION \& EXISTING PROBLEMS IN CHINA's DOMESTIC WORKER MARKET}

\section{A. The Current Situation of China's Domestic Worker Market}

With continuous economic development, people have increasingly high demands on life quality. In recent years, China's domestic worker market is taking shape. Number and quality of domestic workers have been increasing year by year.

From the perspective of demand on services provided by domestic workers, various cities are becoming big employment markets for domestic workers, which need development urgently. Small households will become the mainstream in Chinese society gradually and an aging population will come into being rapidly, in addition to which new modes such as modernization of life and labor socialization will take shape soon, which will lead to people's demand on domestic worker industry directly. Based on survey data about services provided by domestic workers in nine Chinese cities, Shenyang City can provide 96,000 positions for domestic workers currently, among which 40,000 positions are vacant. Wuhan City can provide 100,000 positions for domestic workers currently, among which 90,000 positions are vacant. Nanjing City can provide 360,000 positions for domestic workers currently, among which 240,000 positions are vacant. Number of vacant positions for domestic workers in Tianjin City is increasing by $20 \%$ annually, which represents a stunning speed. Number of domestic workers needed in Beijing reaches about 800,000; however, only 50,000 domestic workers have relevant job qualifications. Shenzhen, among those medium-sized developed coastal cities, needs about 500,000 domestic workers, but less than 70,000 domestic workers have relevant job qualifications, for which the gap between supply and demand is quite stunning. As the priority of domestic services, domestic worker market will gain booming development with growth of the domestic service industry.[1]

\section{B. Major Problems Existing in China's Domestic Worker Market}

\section{1) Large influence of old concepts}

At present, many people still believe that domestic workers are simply responsible for grocery shopping, doing laundry, cooking and babysitting. In fact, against the new social background, connotation of domestic workers has undergone a great promotion. Ministry of Human Resources and Social Security of the People's Republic of China has specific relevant regulations on job qualifications of domestic workers, based on which a strict performance evaluation system is established.

Discrimination against domestic workers can be commonly seen in the society, for which some people believe that domestic workers are humble and inferior[2]. Therefore, a number of people would rather live on minimum subsistence allowance than work as domestic workers, which is wrong. Just like other industries, the domestic worker industry is an indispensable link in China's social development, which is the result of social division of labor. Therefore, domestic workers should face up to their advantages and disadvantages and have a correct assessment on themselves, instead of belittling themselves improperly.

\section{2) Low quality of domestic workers}

Low quality of domestic workers is mainly reflected in the following aspects: Firstly, their cultural quality is relatively low. Due to some deep-rooted old concepts, people completing basic education are usually reluctant to work as domestic workers, so the domestic worker market is filled with long-term migrant workers without formal education. Secondly, domestic workers are unfamiliar with modern household facilities and thus can't use home appliances in their employers' houses, due to which their service quality is 
decreased. Thirdly, some domestic workers have moral decay, such as theft, abuse of those people under their care, etc.

3) Existence of moral decay behaviors despite repeated prohibitions

As for some households in China, hiring domestic workers indicates that these households have no surplus labor to do those works completed by domestic workers or have enough money to hire domestic workers when their family members have spare time. No matter which is the actual situation, the objective result is that employers can't and will not supervise the entire working process of domestic workers. Under the circumstance of asymmetric information, some domestic workers will be indolent or conduct other moral decay behaviors. Employers pay the most attention to this problem and consider it a problem requiring urgent solution.

\section{ANALYSIS ON CAUSES FOR LOW SERVICE QUALITY IN CHINA's DOMESTIC WORKER MARKET}

\section{A. Differences of Living Habits between Domestic Workers and Their Employers}

Coming from rural areas, most domestic workers have totally different living habits compared to their employers. Because of living in the same house, it is unavoidable that such differences lead to conflicts between domestic workers and their employers. For example, some employers complain about domestic workers' poor hygienic habits and their failure to clean cooking utensils and windows. However, these domestic workers believe that they have completed their works in a satisfactory way and their employers are far too harsh on them. Meanwhile, most domestic workers and their employers live together, so family status, moral quality and family privacy of their employers will be disclosed to domestic workers[3]. If domestic workers don't have great awareness about safety and respect for privacy, more severe conflicts of principle between domestic workers and their employers will be caused.

\section{B. Non-Equivalent Relationship between Remuneration and Labor Capacity}

In addition to a fixed amount of monthly salary, domestic workers have accommodation in their employers' houses, which seems quite satisfactory. However, a domestic worker has to complete tedious mental and manual works every day. Although they usually don't face a huge workload, their jobs are quire tedious. In addition, their working hours are uncertain. For example, when looking after new born babies, maternity matrons can't get off work or have a rest at a fixed time and have to focus on newborn babies, for which they don't have fixed work and rest time and thus believe that their remunerations don't match their work. However, employers believe that domestic workers are simply responsible for doing laundry, cooking, house cleaning and babysitting and thus their works contain little technical content, so their remunerations are higher than what they deserve to earn from their works. Different cognitions of domestic workers and their employers will cause conflicts inevitably.

\section{Delayed Transformation of Role}

In order to find reliable domestic workers, many employers often hire their relatives or friends from rural areas to serve as domestic workers and believe that they can not only trust their relatives or friends as domestic workers in doing housekeeping or taking care of their family members but also improve relationships between their relatives or friends and themselves. However, after living in their houses, their relatives or friends as domestic workers are very likely unable to position their roles correctly and will make their employers feel unsatisfactory.

\section{Conflicts Caused by Psychological Differences}

After leaving their families and familiar social environments, domestic workers have to work in totally strange environments and live under supervision of their employers, for which they may suffer psychological disorder to a certain degree. Such circumstance makes most domestic workers feel no freedom and convenience. Moreover, because of little understanding about domestic workers, many employers may have negative evaluations on personalities of their domestic workers, such as arbitrary suspicion against domestic workers, etc. After being misunderstood, physically and psychologically exhausted domestic workers may usually be slack in work or even resign to give vent to their dissatisfaction.

\section{EMERGENCE OF PSYCHOLOGICAL OWNERSHIP}

Psychological ownership was put forward by Dr. Pierce in 1991, according to which psychological ownership refers to the experience of ownership and an individual's feeling of owning the object of (psychological ownership). With emergence of psychological ownership, an employee's sense of responsibility and task sharing will also emerge (Druskat, et al., 1995). Once psychological ownership is established, employees will have the sense of ownership and feel at home in households of their employers. The supreme authority for path research on psychological ownership is Pierce. Pierce and his team put forward three paths for generation of psychological ownership: Control over, close understanding of and personal dedication to the target object.

Firstly, target object should be locked and controlled. Such control may create a sense of owning. After a behavior subject believes that he or she has the ability to use and control a target object, such behavior object will have a sense of ownership towards the target object which can be controlled by him/her.

Secondly, close understanding serves as a path. An individual's sense of owning will be deepened with his or her closer understanding about a target object. The more deepened such understanding about a target object, the more closer connection between the individual and the target object, which will leads to generation of the individual's sense of ownership towards such target object.

Thirdly, personal dedication serves as the third path. It will be increasingly easy for an individual to have a sense of ownership towards a target object with more resources of the 
individual, such as time and energy, being invested into such target object. When time, energy and intelligence invested by an individual lead to integration of the behavior subject and a target object in a conscious manner, the behavior subject has a sense of ownership towards the target object.

The above three paths will have an influence on generation of psychological ownership eventually.

\section{Measures FOR IMProving SERVICE QuALiTy in DOMESTIC WORKER MARKET}

As for employers, their ultimate goal is to improve happiness index of their families and themselves through full integration of domestic worker resource. How to realize efficient management on domestic workers is a core issue. Effective motivation of domestic workers is the only method to solve various problems existing in China's domestic worker market. The theory of psychological ownership provides a new perspective for solving the problem of insufficient motivation in China's domestic worker market.

\section{A. Managers Should Establish the Awareness of Psychological Ownership.}

The most effective way to improve the effectiveness of employees' participation in decision-making process is to make them believe that their participation in decision-making process is legal and reasonable. Attitude of an employer plays a critical role in reconciling the relationship between domestic worker and him/her and increasing service quality of domestic workers. It isn't necessary to make sure that a domestic worker's objective sense of ownership is identical to her expected ownership. If an employer lacks necessary sense of responsibility and relevant awareness of respect, and a domestic worker can perceive such attitude and has objective or subjective evidence showing the employer's attitude towards her participation at various degrees (clearly or indefinitely), such circumstance will prevent an official participation mechanism from generating necessary expected result to a large extent. Therefore, employers should attach importance to their domestic worker, utilize their capabilities in a reasonable manner and make them feel at home in order to establish a sense of ownership and the consciousness of devotion, through which enthusiasm and initiative of domestic workers in their work can be improved and maintained and they can not only complete their work duties in an outstanding way but also complete their extra duties under great motivation.

\section{B. Paths to Open up Psychological Ownership}

1) Efforts should be made to improve domestic workers' sense of control over their work and life.

Some scholars once pointed out: When employees have more control power and more rights to be informed in their work and life, it is easier for them to establish and maintain their psychological ownership and thus reinforce their commitment to their organizations. Domestic workers live in their employers' houses, for which employers should grant more freedom and provide as more information as possible to domestic workers in order to enable them to control more matters and articles and improve their control over job and thus increase the possibility of generation of psychological ownership. If an employer conducts centralization of power to an extreme degree, amount of control held by domestic workers may easily be reduced. Facing such household, it will be very difficult for a domestic worker to have a sense of ownership towards anything. When domestic workers don't own a household or any part of it, they may reduce their dedication or choose to leave.

\section{2) Sense of intimacy should be improved through efficient} communication

Employers may help domestic workers to generate psychological ownership towards their households through improving sense of intimacy. Sense of intimacy may be improved through a number of methods. Pierce believes that efforts may be made to enable members of an organization to perceive relevant information about the organization in an easier way, or cost paid by employees for collecting information about an organization may be decreased as much as possible, through which expected result may be achieved. Based on such theory, employers may provide enough opportunities to domestic workers in participating in family affairs and provide them more convenient conditions and channels in order to help domestic workers know about their family status and improve degree of close connection between domestic workers and those households in which they do their job.

3) Dedication of domestic workers in their job should be improved and maintained in a scientific way.

For successful employers, they should not only be responsible for helping domestic workers realize job objectives but also using scientific methods to help them realize expected job objectives. When necessary, employers should also provide corresponding assistance and psychological guidance. When an individual becomes more dedicated to a target object, it is easier for him or her to have psychological ownership and a sense of responsibility toward the organization and his or her job[4]. Such reinforced emotional bond between domestic workers and households of their employers can not only increase domestic workers' dedication to their works but also make them have a sense of being at home when working in their employers' households, which increases their sense of belonging and sense of ownership. Domestic workers need to feel that their employers are loyal and responsible and they are welcome in households of their employers. Support and attention of employers can satisfy such psychological desire of domestic workers to a large extent, make them perceive and confirm their status and roles in their employers' households and increase their sense of dedication and responsibility toward their employers' households and their works. Such positive emotional experiences can not only promote generation of psychological ownership but also facilitate the establishment of great interpersonal relationship between domestic workers and their employers. 


\section{Sense of Ownership Should Be Integrated Into Family Culture}

Each family has its own family culture corresponding to its characteristics. Families hiring domestic workers should ensure and secure domestic workers' sense of ownership, instead of excluding them. Implementing such sense of ownership everywhere in family culture serves as the only method to make domestic workers feel and influenced by warmth and harmonious atmosphere in their employers' households actually. Families hiring domestic workers should make efforts to attach appropriate importance to domestic workers in order to let them feel the human-oriented concept of these households and thus make domestic workers realize coordination between their personal objectives, work objectives and family objectives of their employers, in addition to which domestic workers' sense of belonging can be cultivated during the process of giving full play to subjective initiative of domestic workers. To make a domestic worker become an integral part of a community of interests, employers should make domestic workers think the same way, for which generating sense of ownership of domestic workers serves as a great method for realize this original intention.

\section{Motivation Method Combining Hardness and Softness}

Compared to hard motivation, soft motivation is a new and more flexible motivation concept. Core concept of soft motivation is human-oriented concept. As for domestic worker market, soft motivation theory emphasizes the use of appropriate motivation methods based on physical, psychological and behavioral laws, which are non-mandatory.
Such non-mandatory method can motivate potential of domestic workers and their self-discipline, which will lead to the transformation of employers' wills into conscious personal activities of domestic workers. Soft motivation is based on coordinated development of domestic workers and their employers' households, which is time-based to a certain degree.

\section{CONCLUSION}

To sum up, discussion on issue of service quality in China's domestic worker market in this paper proceeds from psychological ownership theoretically, based on which approaches and methods to help domestic workers establish sense of ownership are analyzed and their sense of belonging based on the feeling of being at home in their employers' households can be established. This paper may be used for reference as for development and application of localization of psychological ownership theory.

\section{REFERENCES}

[1] Harrison G W,Morgan P. Search intensity in experiments[J]. The Economic Journal,1990,100(401) : $478-486$.

[2] Cox J C,Oaxaca R L. Good news and bad news: Search from unknown wage offer distributions[J]. Experimental Economics, 2000,2(3):197 — 225.

[3] Henriette Jastrow. Domestic Servants in Germany. Their Economic, Social and Legal Position. The Economic Journal ,1899,P625-633.

[4]Nicole Constable. Pierrette Hondagneu_sotela and Hrnestine Avila, 2000, P154. 